\title{
Development and Commissioning of High Temperature FBG Solid Pressure Sensors
}

\author{
Hong-Ying Guo $\mathbb{D}^{1,2}$ Zhao-Ba Wang $\mathbb{D}^{1},{ }^{1}$ and Hai-yang $\mathrm{Li}^{1}$ \\ ${ }^{1}$ School of Information and Communication Engineering, North University of China, Taiyuan 030051, China \\ ${ }^{2}$ Department of Electronics, Xinzhou Teachers University, Xinzhou 034000, China \\ Correspondence should be addressed to Zhao-Ba Wang; wangzb@nuc.edu.cn
}

Received 6 March 2018; Revised 20 May 2018; Accepted 2 July 2018; Published 2 August 2018

Academic Editor: Banshi D. Gupta

Copyright ( 2018 Hong-Ying Guo et al. This is an open access article distributed under the Creative Commons Attribution License, which permits unrestricted use, distribution, and reproduction in any medium, provided the original work is properly cited.

\begin{abstract}
In this work, a new type of high temperature fiber grating diaphragm pressure sensor is described, including the physical design structure, in-depth analysis of optical response to changes in pressure, and a discussion of the temperature compensation method. Mathematical model of high-temperature compressive shape change and normal-temperature compressive shape change is built, and effective temperature compensation method is proposed, which can both contribute to solve temperature interference of pressure sensor at high temperature. In addition, the simulation computation is conducted for the external encapsulation of the sensor under the high-temperature and pressure according to the design model. Through analysis and comparison of data affecting the changing position of grating signal, the correctness of the simulation result is verified by the development of the prototype. The temperature compensation method is proposed to realize pressure measurement of sensor with a relative error below $4.6 \%$ F.S. and range to $50 \mathrm{MPa}$ in the environment of 300 , which meets with the safety research requirement of the cartridge system.
\end{abstract}

\section{Introduction}

Solid internal pressure in a high temperature environment is an important index in the field of safety and environmental adaptability of the ammunition system. It is the necessary basis for judging whether the whole structure (projectile body) will cause partial or overall instability and failure, which will result in the loss of stability due to the excessive deformation caused by thermal expansion [1], such as solid rocket engine propellant internal pressure, the weapon system inside the warhead internal fire, and explosive pressure, which all require the detection of internal pressure in a high temperature environment. Fiber Bragg grating (FBG) has been proposed and widely used in the optic communication and sensing fields due to their prominent advantages, such as immunity to electromagnetic noise, small profile, lightweight, and high resistance to hostile environments [2-4]. Fiber grating sensor technology exists everywhere in our daily lives, with the advantages of environmental friendliness, effectivity, and sustainability. On this basis, fiber Bragg grating (FBG) sensor has been put forward and widely applied in bridge, landslide safety monitoring [5-8]. The fact that multiple FBGs can be arrayed along a single fiber, various FBG sensors for temperature, pressure, strain, displacement, vibration, and acceleration measurement have been developed and could be applied to the same engineering applications. Pressure sensor based on fiber Bragg grating is feasible for long distance distributed monitoring without on-site power supply. Especially in flammable and explosive, electromagnetic interference, and strong radiation in the harsh environment, it can easily reflect a huge advantage, which can be used in solid pressure testing frequently $[9,10]$. The pressure measurement based on FBG is a kind of common sensing technology, and the pressure monitoring can be realized indirectly by checking the parameters of strain and physical measuring object of fiber Bragg grating $[11,12]$. The FBG sensor for direct force measurement has also been reported in literature $[13,14]$. Many researchers focus on the field of fiber Bragg grating sensing pressure technology. In 2013, Huang et al. [15] reported a diaphragm-type fiber Bragg grating pressure 
sensor with temperature compensation. The sensor adopts a circular diaphragm with two FBGs adhered on the surface along the radial direction as the pressure sensitive component. The experiment results indicate that the pressure sensitivity of this novel sensor is as high as $1.57 \mathrm{pm} /$ $\mathrm{kPa}$. In 2014, Pachava et al. [16] designed a highly sensitive FBG pressure sensor using a thin metal diaphragm. The experimental pressure sensitivity of the sensor is $2.05 \times 10^{-2} \mathrm{MPa}^{-1}$. In 2015, Allwood et al. [17] designed a highly sensitive fiber Bragg grating diaphragm pressure transducer. The results show that the transducer has a sensitivity of $0.116 \mathrm{~nm} / \mathrm{kPa}$. However, most of these pressure FBG sensor were limited by the pressure-measuring range and operating temperature. The pressure-measuring range of the above-mentioned sensors is within $25 \mathrm{MPa}$, and the required temperature is $15^{\circ} \mathrm{C}-50^{\circ} \mathrm{C}$ [15-18].Obviously that cannot meet the demand of pressuremonitoring in the projectile when heated (working temperature: $300^{\circ} \mathrm{C}$, pressure range: $50 \mathrm{MPa}$ ). In addition, the high sensitivity of these sensors is obtained through the materials with low elastic modulus such as rubber and aluminum [3, 4, 9, 15-17]. These sensors will inevitably be damaged if applied to the safety and environmental adaptability of the ammunition system. For these reasons, it is necessary to research pressure sensors with high temperature and pressure.

Here, we design and present a FBG pressure sensor with high temperature and pressure. In our previous work, the research team has carried out the study of high pressure solid pressure sensor of fiber Bragg grating [19]. In this design, the sensitivity of the sensor is improved completely through the design of the structure. When the pressure perpendicular to the plane of the sensor model is loaded, the structure can convert the pressure into two $X$ direction deformations of the two fixed column. In the $\mathrm{Y}$ and $\mathrm{Z}$ directions, the two fixed columns have the same deformation and no relative change. When the grating is pasted between two fixed columns, the change in pressure produces only axial strain without radial strain. It can be seen in Figures 1(a)-3(a) of support information (available here). In order to meet the normal working requirements under $300^{\circ} \mathrm{C}$, we have realized the ideal pressure-measuring effect, and we used the grating (limit temperature $400^{\circ} \mathrm{C}$ ) which is inscribed on the SMF-28e optical fiber coated with polyimide. The sensor structure which is suitable for high-temperature and high-pressure environment is proposed to make fiber Bragg grating high temperature and pressure-resistant sensors. In a high-temperature environment, the external metal packaging will expand deformation, resulting in grating signal fluctuations and serious pressure measurement errors; therefore, temperature compensation is needed. In this paper, the deformation data of the sensor outer package under different pressure at ambient temperature, the load-free at different temperatures, and the load of $50 \mathrm{MPa}$ pressure are simulated, respectively; $100 \sim 300^{\circ} \mathrm{C}$ of the transducer housing under the above conditions are obtained, and a reasonable temperature compensation method is obtained. By using the method of temperature compensation, the measurement of the sensor's relative error is below $0.836 \%$, and the range $50 \mathrm{MPa}$ is realized under the environment of $300^{\circ} \mathrm{C}$, all of which satisfy the requirement of the security research of the ammunition system.

\section{Working Principle and Sensor Structure Design}

FBG is an optical wavelength modulation component. When a beam of broadband light wave is incident on FBG, the optical wave with the wavelength satisfying Bragg equation after modulation by Bragg grating is coupled by Bragg grating to the inverse transmission mode [20] and form Bragg equation of Bragg reflection wave:

$$
\lambda=2 n_{\text {eff }} \Lambda \text {. }
$$

In (1), $\Lambda$ is the pitch of grating and $n_{\mathrm{eff}}$ is the effective refractive index of optical grating. Both $\Lambda$ and $n_{\text {eff }}$ change owing to the impact of outer world (temperature, strain, pressure, etc.), which causes the reflection wavelength of optical grating moves. The center reflection wavelength of FBG is affected by the temperature and strain. The relationship among wavelength change, axial strain change, and temperature change response $[21,22]$ is:

$$
\frac{\Delta \lambda}{\lambda}=\left(\alpha_{f}+\xi\right) \Delta T+\left(1-P_{e}\right) \Delta \varepsilon
$$

In (2), $\lambda$ is the initial wavelength of FBG, $\alpha_{f}$ is the thermal expansion coefficient, $\xi$ is the thermo-optical coefficient, and $P_{e}$ is the effective photoelastic coefficient. The effective photoelastic coefficient at indoor temperature is 0.22 .

The pressure sensitivity of bared grating is low, and it is easy to break off and unpressurized. Thus, it is unsuitable for conventional measurement. We must encapsulate it so as to reach the purpose of pressure sensitivity and compression resistance [23-25]. According to solid mechanics and current research result of matching error of solid sensor [14], if the sensor is designed into cake shape, it can obtain ideal test value. In the design, optical grating pressure sensor with high temperature resistance is designed adopting optical grating with high temperature resistance whose surface is coated with heat-resistant material on the basis of the encapsulation structure of traditional optical grating sensor. The encapsulation structure diagram of sensor is shown in Figure 1.

Solid pressure sensor of optical grating is composed of pressure-bearing membrane, sensor enclosure, and stainless steel top cover. All these three components are made from the same substrate materials. The pressure-bearing membrane is made up of circular elastic membrane and fixed column. The fixed column and elastic membrane as well as the sensor enclosure are formed by wholistic processing so as to reduce the stress concentration or stress nonuniformity problem. The sensor enclosure and SS cover adopt threaded connection. The pressure-bearing part adopts elastic membrane as the elastic component of sensor and two symmetric fixed columns are used for fixing both ends of inductive fiber 


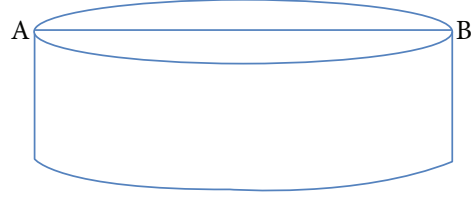

(a)

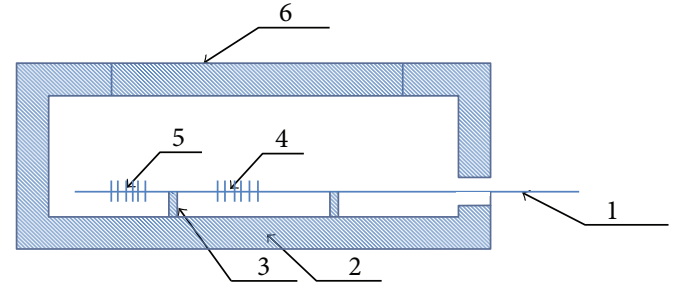

(b)

FIgURe 1: Structural diagram of optical grating pressure sensor. (a) Outline of sensor. (b) Structural profile at AB position. (1) Fiber, (2) fixed column, (3) pressure diaphragm, (4) strain grating FBG1, (5) temperature compensation grating FBG2, (6) stainless steel cover.

Bragg grating 1 (FBG1). The elastic shape change of circular elastic membrane transforms the solid pressure into the measurable strain of optical grating. FBG2 is temperaturecompensating grating. It is only affected by temperature but without being affected by the enclosure shape change. It is used for realizing temperature compensation. Diameter $R$ of the sensor is selected as $120 \mathrm{~mm}$, the thickness of wall $h$ is $15 \mathrm{~mm}$, the spacing $l$ of two fixed center points $l$ is $40 \mathrm{~mm}$, the diameter $r$ of fixed column is $10 \mathrm{~mm}$, and the height $m$ of fixed column is $10 \mathrm{~mm}$. When external force acts on the pressure-bearing membrane, the membrane behaves small deflection deformation, and the distance between two fixed columns widens. We pull the grating and measure the changing reflection signal and further get applied load information. Therefore, the research of the impact of temperature and pressure to the sensor enclosure focuses on studying the change of the distance between fixed columns due to these factors. There are two factors affecting the distance change of these two fixed columns: (1) the horizontal displacement of the membrane where the fixed columns are ( $x$-axis displacement) and (2) the horizontal projection of fixed columns (directionally proportion to $z$-axis deformation). The superposition of these two factors decides the distance change of two fixed columns. According to the sensor enclosure structure, it is known: (3)

$$
\Delta l=\left(\Delta x_{r}-\Delta x_{l}\right)+\frac{2 m \Delta z}{R} .
$$

\section{Pressure Test and \\ Temperature Compensation}

3.1. Compressive Structure Analysis at Normal Temperature. To obtain the deformation distribution of the sensor enclosure under different pressure, the paper simulates loading using finite element method (ANSYS15). An elastic material made from 304\# stainless steel is used for parameter simulation as follows: Young modulus $E=1.942 \times e^{11} \mathrm{~Pa}$, Poisson's ratio $\mu=0.28$, and loading pressure $50 \mathrm{MPa}$. Simulation results are shown in Figures 2-5, Figure 2 is the total deformation figure of the sensor model in $50 \mathrm{MPa}$ pressure, Figures 3, 4, and 5, respectively, is the directional deformation of the $\mathrm{X}, \mathrm{Y}, \mathrm{Z}$ direction distribution of the sensor model in $50 \mathrm{MPa}$ pressure.

According to the figure above, it can be seen that, after applying pressure, the membrane produces small deflection deformation downward. Two symmetric fixed columns relative to origin are put on the inside wall of the membrane with the diameter $y=0$. The two fixed columns are symmetric relative to origin, so the displacement at $z$-axis is the same, the displacement direction at $y$-axis is opposite, and the displacement direction at $x$-axis is opposite. In this way, both ends of optical grating are stuck to the fixed column, the radial shape change of optical grating is eliminated and there is only axial shape change ( $x$-axis direction).

After adding two fixed columns, in the case where the simulated parameter and added load are constant, the internal deformation diagram of the sensor model is shown in Figures 6 and 7. Figure 6 is the overall deformation diagram inside the sensor. Figure 7 shows the deformation distribution of the internal $\mathrm{X}$ direction of the sensor.

According to Figure 7, it can be seen that the deformation of two fixed columns at $x$-axis is the most remarkable and the directions are opposite. Fixing both ends of optical grating on two fixed columns can make the sensor gain maximum sensitivity.

The diameter passing through two fixed columns in Figure 8 is selected as the path. The deformation distribution of each point on this path under the pressure of $50 \mathrm{MPa}$ is shown in Figure 8. The deformation data at two fixed columns under different loads are shown in Table 1.

It can be seen from the above table that the external load is linear between the central points of the two fixed columns, and the two ends of the grating can be bonded to the fixed column to detect the external load. The external pressure is proportional to the distance between the two fixed columns, and the relation is:

$$
P=K_{d} \Delta l \text {. }
$$

In formula (4), $P$ is the external pressure and $\Delta l$ is the change of the distance between the two fixed columns. Substitute formula (3) into formula (4), we get:

$$
P=K_{d}\left(\left(\Delta x_{r}-\Delta x_{l}\right)+\frac{2 m \Delta z}{R}\right) .
$$

Substitute the data in Table 1 , we get $K_{d}=670.48396 \mathrm{M}$ $\mathrm{Pa} / \mathrm{mm}$.

\subsection{Impact of Temperature Change on Pressure Test and Temperature Compensation Method}




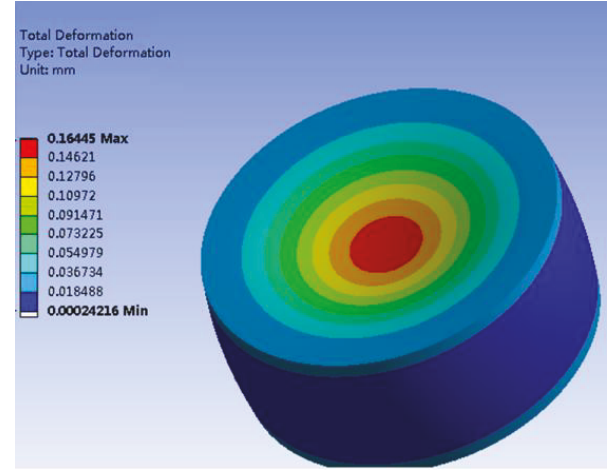

FIgURE 2: Total deformation of sensor outer casing.

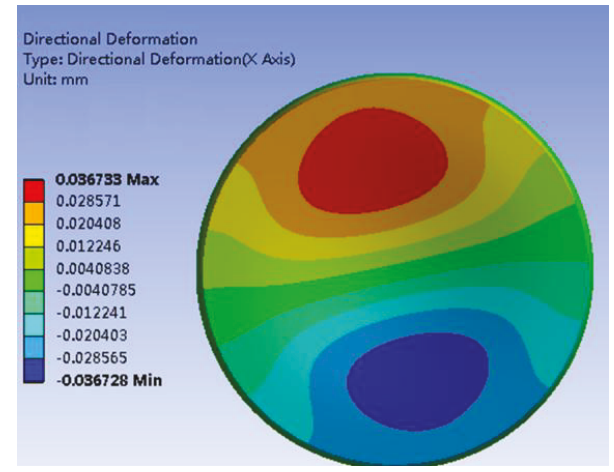

FIGURE 3: $x$-axis deformation of the sensor outer casing.

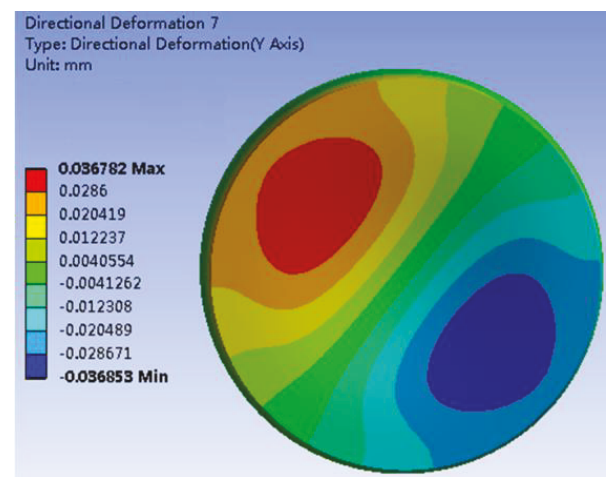

FIgURE 4: $y$-axis deformation of the sensor outer casing.

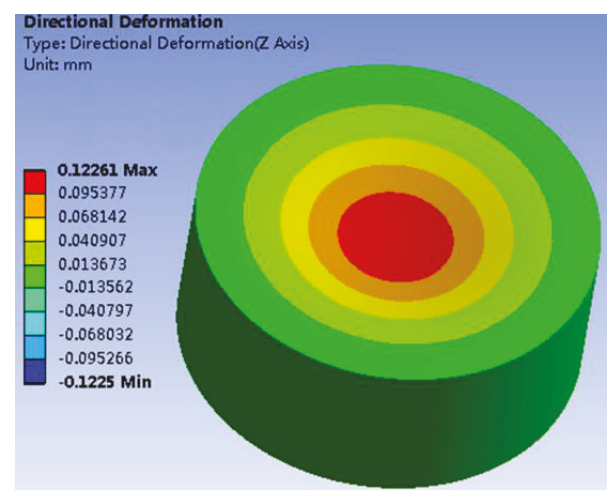

FIGURE 5: $z$-axis deformation of the sensor outer casing.

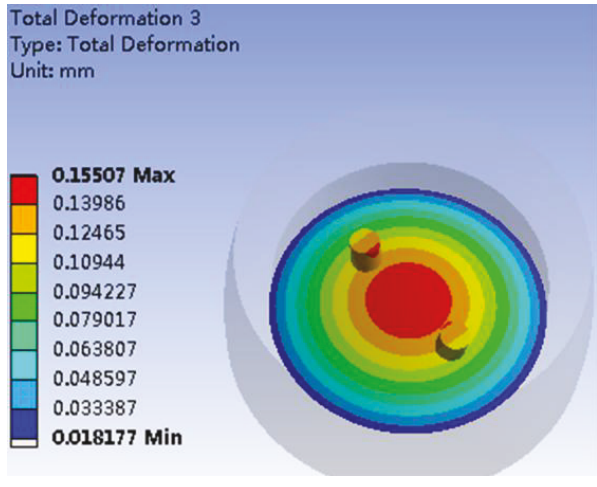

Figure 6: Total deformation of inside sensor casing.

3.2.1. Structural Deformation at Different Temperature and Its Impact. The external model of the sensor is simulated at different temperature without any loads applied. The parameter simulated is as below: heat conductivity $16.2 \mathrm{~W} / \mathrm{m}^{\circ} \mathrm{C}$, linear expansion coefficient $17.3 \times 10^{-6} /{ }^{\circ} \mathrm{C}$, Young modulus $E=1.942 \times e^{11} \mathrm{~Pa}$, and Poisson's ratio $\mu=0.28$. The deformation of the sensor model under the $300^{\circ} \mathrm{C}$ environment without pressure is shown in Figure 9.

The diameter of compressive membrane passing through two fixed columns is selected as the path. At different temperatures without pressure, the deformation data at $x$-axis of two fixed columns and $z$-axis of the center of the membrane is shown in Table 2.

From Table 2, we can see that at high temperature, the sensor shell is heated and expanded, which will cause the grating reflection wavelength to change and result in the error of pressure measurement. Effective temperature compensation must be adopted to counteract the effect of temperature.

3.2.2. Temperature Compensation Method. Taking the above model under the pressure of $50 \mathrm{MPa}$ at $300^{\circ} \mathrm{C}$, the material is 304\# steel. The following parameters are used to simulate: the thermal conductivity 16.2 and linear expansion coefficient 17.3, Young modulus $E=1.942 \times e^{11} \mathrm{~Pa}$, and Poisson's ratio $\mu=0.28$. The result of simulation is as shown in Figure 10 .

The diameter of two fixed columns on the compressive membrane is selected as the path. The deformation data of each point of this path at $300^{\circ} \mathrm{C}$ before and after applying $50 \mathrm{MPa}$ load are compared as Figures 11 and 12. Figure 11 shows the $x$-axis deformation data, and Figure 12 is the deformation data of $z$-axis direction.

In Figures 11 and 12, the red, black, blue, and pink curves are the deformation distribution of each point on this path under different environment. The red is under the $300^{\circ} \mathrm{C}$ environment without pressure. The black is under the $300^{\circ} \mathrm{C}$ environment and the pressure of $50 \mathrm{MPa}$. The blue is shown the difference under the $300^{\circ} \mathrm{C}$ environment between with $50 \mathrm{MPa}$ pressure and without pressure. The pink curve is at room temperature with $50 \mathrm{MPa}$ pressure. As it can be seen from Figures 11 and 12, the blue curve and the pink curve almost coincide; thus, it indicates that the deformation under the same pressure at different temperature is consistent, and the deformation which is due to temperature and 


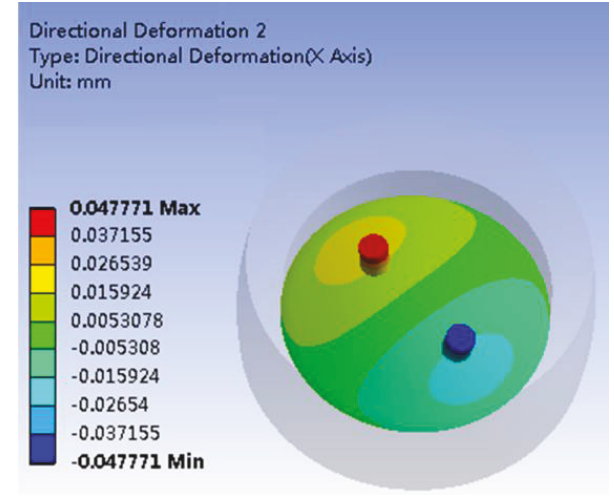

Figure 7: $x$-axis deformation of inside sensor casing.

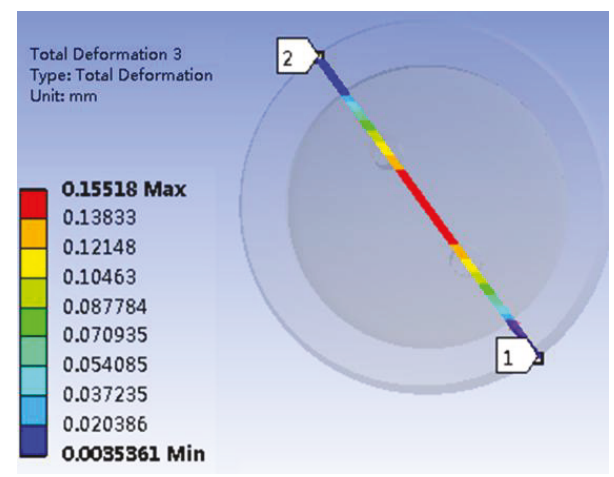

Figure 8: Path deformation.

Table 1: Deformation under different pressure.

\begin{tabular}{lccc}
\hline $\begin{array}{l}\text { Pressure } \\
(\mathrm{MPa})\end{array}$ & $\begin{array}{c}x \text {-axis deformation } \\
\text { of left fixed } \\
\text { columns }(\mathrm{mm})\end{array}$ & $\begin{array}{c}x \text {-axis deformation } \\
\text { of right fixed } \\
\text { columns }(\mathrm{mm})\end{array}$ & $\begin{array}{c}z \text {-axis } \\
\text { deformation } \\
\text { of center } \\
(\mathrm{mm})\end{array}$ \\
\hline 10 & $5.47 \mathrm{E}-03$ & $-5.48 \mathrm{E}-03$ & $3.20 \mathrm{E}-02$ \\
20 & $1.10 \mathrm{E}-02$ & $-1.10 \mathrm{E}-02$ & $6.41 \mathrm{E}-02$ \\
30 & $1.64 \mathrm{E}-02$ & $-1.65 \mathrm{E}-02$ & $9.62 \mathrm{E}-02$ \\
40 & $2.19 \mathrm{E}-02$ & $-2.19 \mathrm{E}-02$ & $1.28 \mathrm{E}-01$ \\
50 & $2.74 \mathrm{E}-02$ & $-2.75 \mathrm{E}-02$ & 0.16056 \\
\hline
\end{tabular}

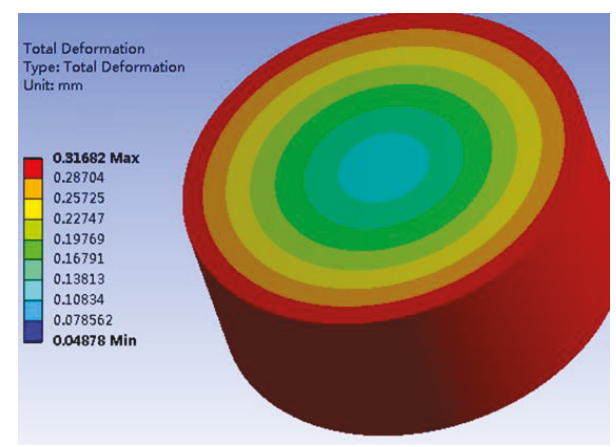

Figure 9: Load-free deformation pattern at $300^{\circ} \mathrm{C}$. pressure is linear superposition. We can adopt the signal change caused by thermal deformation under no load after using the measured signal minus the corresponding temperature. That is, the signal change caused by pressure and the deformation caused by pressure at high temperature are nearly totally identical to the deformation caused by the same pressure at normal temperature and the error rate is lower than $0.1 \%$. Thus, the normal temperature formation approximates high temperature deformation.

The diameter of two fixed columns is taken as the path. The deformation data on two fixed columns at different temperature, the deformation data at corresponding temperature after applying $50 \mathrm{MPa}$ load, and that at normal temperature after applying $50 \mathrm{MPa}$ are compared in Table 3 .

According to Table 3, it is concluded that the deformation difference at different temperature after applying $50 \mathrm{MPa}$ pressure and applying no load is consistent with the deformation at normal temperature after applying $50 \mathrm{MPa}$ pressure. In the actual test, the optical grating wavelength change at high temperature under stain includes the wavelength change triggered by the impact of temperature on optical grating, thermal deformation, and pressure: (a) A sensor is put in the thermostat to test the wavelength change (b) at different temperature without load. For temperature-compensated optical grating FBG2, owing to the impact of temperature, the wavelength change is $\Delta \lambda_{2 T}$. Through wavelength change of temperature-compensated optical grating, it is seen that the temperature of the sensor is $\Delta T$. According to $\Delta T$, we get a corresponding $\Delta \lambda_{T}$, and the pressure at current temperature:

$$
\Delta P=\frac{\left(\Delta \lambda_{1}-K_{1 d}{ }^{*} \Delta T\right)}{K}=\frac{\left(\Delta \lambda_{1}-K_{1 d}{ }^{*} \Delta \lambda_{2 T} / K_{2 t}\right)}{K} .
$$

In formula (6), $\Delta P$ is the pressure loaded on the sensor, $\Delta \lambda_{1}$ is the measured wavelength change of pressure sensitive grating, $K$ is pressure-wavelength coefficient under normal temperature, $\Delta \lambda_{2 T}$ is the wavelength change of the temperature compensated optical grating, $K_{2 t}$ is the temperature coefficient of temperature-compensated grating, and $K_{1 d}$ is the temperature coefficient of pressure sensitive grating. These parameters can be measured by experiment. In this way, the pressure at high temperature is measured.

\subsection{Experimental Calibration}

3.3.1. Temperature Experiment. The sensor was put into the temperature test box. The preparation part of the experiment is: the sensor is heated from $20^{\circ} \mathrm{C}$ to $300^{\circ} \mathrm{C}$, and then the temperature drops naturally from $300^{\circ} \mathrm{C}$ to $20^{\circ} \mathrm{C}$. The experiment is conducted three times. Then, the output of the sensor's pressure sensitive FBG and temperature compensation FBG was recorded when the temperature went up from $100^{\circ} \mathrm{C}$ to $300^{\circ} \mathrm{C}$, with same intervals of $20^{\circ} \mathrm{C}$. During the process, each temperature point should be kept unchanged for 2 hours. Similarly, the output of pressure sensitive FBG and temperature compensation FBG was recorded with $1 \mathrm{~h}$ temperature keeping at each temperature point. Taking the average value 
TABLE 2: Deformation data at different temperature.

\begin{tabular}{lcccc}
\hline $\begin{array}{l}\text { Temperature } \\
\left({ }^{\circ} \mathrm{C}\right)\end{array}$ & $\begin{array}{c}x \text {-axis deformation of left fixed } \\
\text { columns }(\mathrm{mm})\end{array}$ & $\begin{array}{c}x \text {-axis deformation of right fixed } \\
\text { columns }(\mathrm{mm})\end{array}$ & $\begin{array}{c}z \text {-axis deformation of } \\
\text { center }(\mathrm{mm})\end{array}$ & $\begin{array}{c}\text { Cause deviation } \\
(\mathrm{MPa})\end{array}$ \\
\hline 100 & $2.61 \mathrm{E}-02$ & $-2.79 \mathrm{E}-02$ & $-3.69 \mathrm{E}-02$ & 32.070477 \\
140 & $3.95 \mathrm{E}-02$ & $-4.22 \mathrm{E}-02$ & $-5.58 \mathrm{E}-02$ & 48.5168898 \\
180 & $5.29 \mathrm{E}-02$ & $-5.65 \mathrm{E}-02$ & $-7.47 \mathrm{E}-02$ & 64.9631909 \\
220 & $6.63 \mathrm{E}-02$ & $-7.08 \mathrm{E}-02$ & $-9.36 \mathrm{E}-02$ & 81.4096037 \\
260 & $7.96 \mathrm{E}-02$ & $-8.51 \mathrm{E}-02$ & -0.11249 & 97.8555695 \\
300 & $9.30 \mathrm{E}-02$ & $-9.94 \mathrm{E}-02$ & -0.13139 & 114.302541 \\
\hline
\end{tabular}

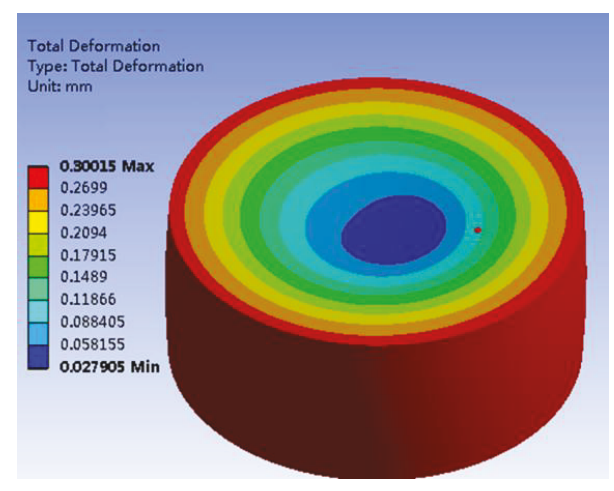

Figure 10: $50 \mathrm{MPa}$ deformation pattern at $300^{\circ} \mathrm{C}$.

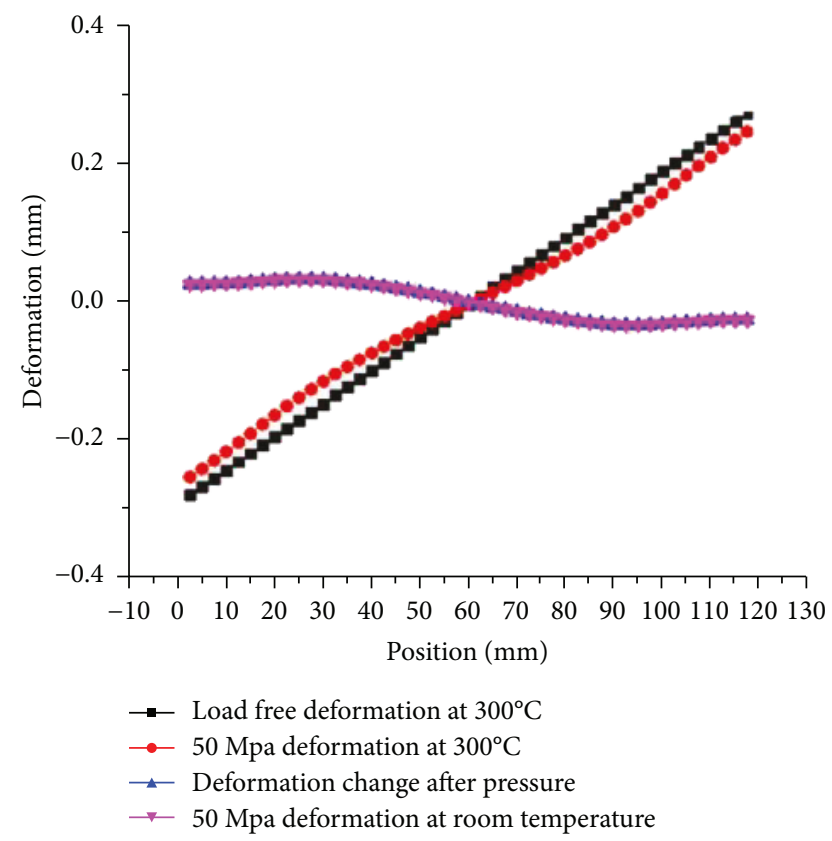

FIGURE 11: $x$-axis deformation pattern of point on the path.

of the output caused by the temperature change of the positive and inverse range as the verification value to carry on data analysis and processing. The sensitivity of the sensor's pressure sensitive grating FBG1 and temperature compensation grating FBG2 to temperature response can be obtained. The temperature response curve is shown in Figure 3. Using $+20^{\circ} \mathrm{C}$ as the reference, the drift characteristic curve of the relation between center wavelength of the pressure sensitive

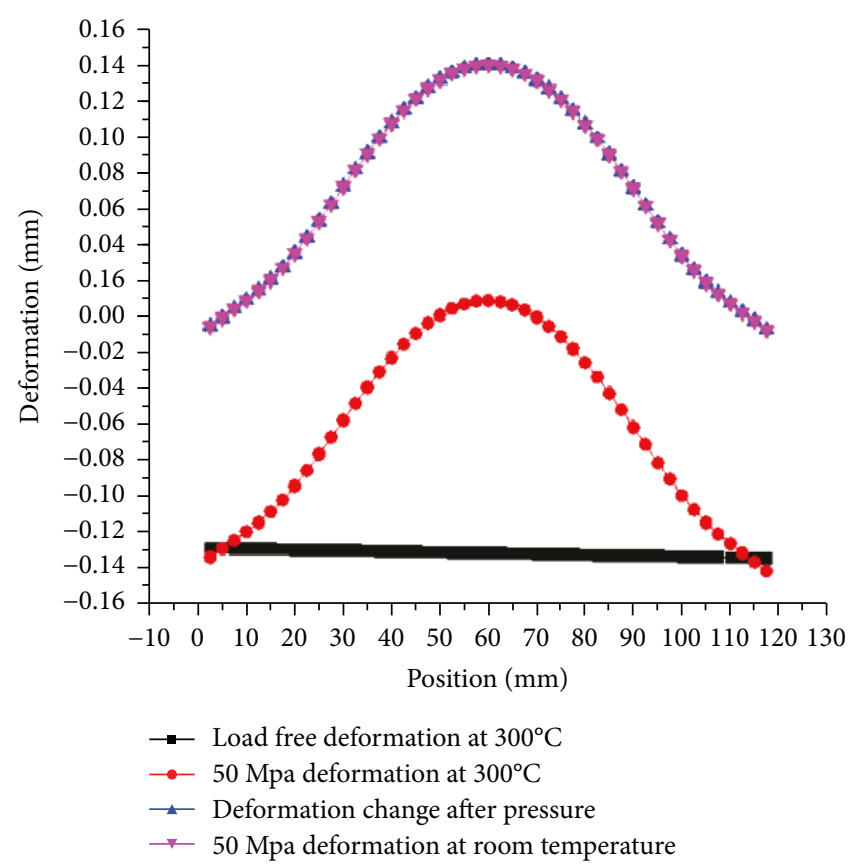

FIgURE 12: $z$-axis deformation pattern of point on the path.

grating (FBG1) after temperature compensation under zero pressure load and temperature can be attained by the process of formula (6), as shown in Figure 13.

3.3.2. Temperature and Pressure Cross Experiment. The sensor was placed in a high temperature pressure furnace and tested at $100^{\circ} \mathrm{C}, 150^{\circ} \mathrm{C}, 200^{\circ} \mathrm{C}, 250^{\circ} \mathrm{C}$, and $300^{\circ} \mathrm{C}$, respectively. The pressure-wavelength data of the sensors at different temperature points were recorded, and the curves were drawn (shown by Figure 14).

\section{Conclusion}

To meet the requirement of safety and adaptability detection of the cartridge system, the paper proposes a sensor structure applicable to the high temperature and pressure environment. In the mode of ANSYS simulation, the paper discloses the deformation characteristic of the sensor at high temperature and proposes corresponding temperature compensation method, and the correctness of the simulation result is verified by the development of the prototype. In this paper, the corresponding temperature compensation method is put 
TABLE 3: Data comparison before and after applying load at different temperature.

\begin{tabular}{lccccccc}
\hline \multirow{2}{*}{ Temperature $\left({ }^{\circ} \mathrm{C}\right)$} & \multicolumn{2}{c}{$\Delta x_{l}-\Delta x_{r}(\mathrm{~mm})$} & \multicolumn{2}{c}{$\Delta z(\mathrm{~mm})$} & \multicolumn{2}{c}{$\begin{array}{c}\text { Change after pressure } \\
(\mathrm{mm})\end{array}$} \\
& No load & $50 \mathrm{MPa}$ & No load & $50 \mathrm{MPa}$ & $\Delta x_{l}-\Delta x_{r}$ & $\Delta z$ & \multicolumn{2}{c}{ Relative error (\%) } \\
\hline 100 & $5.40 \mathrm{E}-02$ & $2.85 \mathrm{E}-03$ & $-3.69 \mathrm{E}-02$ & 0.1034 & $-5.11 \mathrm{E}-02$ & $1.40 \mathrm{E}-01$ & 0.065 \\
140 & $8.17 \mathrm{E}-02$ & $3.06 \mathrm{E}-02$ & $-5.58 \mathrm{E}-02$ & $8.45 \mathrm{E}-02$ & $-5.11 \mathrm{E}-02$ & $1.40 \mathrm{E}-01$ & 0.081 \\
180 & $1.09 \mathrm{E}-01$ & $5.83 \mathrm{E}-02$ & $-7.47 \mathrm{E}-02$ & $6.55 \mathrm{E}-02$ & $-5.07 \mathrm{E}-02$ & $1.40 \mathrm{E}-01$ & 0.641 \\
220 & $1.37 \mathrm{E}-01$ & $8.60 \mathrm{E}-02$ & $-9.36 \mathrm{E}-02$ & $4.66 \mathrm{E}-02$ & $-5.10 \mathrm{E}-02$ & $1.40 \mathrm{E}-01$ & 0.258 \\
260 & $1.65 \mathrm{E}-01$ & $1.14 \mathrm{E}-01$ & -0.11249 & $2.77 \mathrm{E}-02$ & $-5.13 \mathrm{E}-02$ & $1.40 \mathrm{E}-01$ & -0.124 \\
300 & $1.92 \mathrm{E}-01$ & $1.41 \mathrm{E}-01$ & -0.13139 & $8.77 \mathrm{E}-03$ & $-5.06 \mathrm{E}-02$ & $1.40 \mathrm{E}-01$ & 0.836 \\
Room temperature & 0 & $-5.12 \mathrm{E}-02$ & 0 & 0.14031 & $-5.12 \mathrm{E}-02$ & $1.40 \mathrm{E}-01$ & 0.000 \\
\hline
\end{tabular}

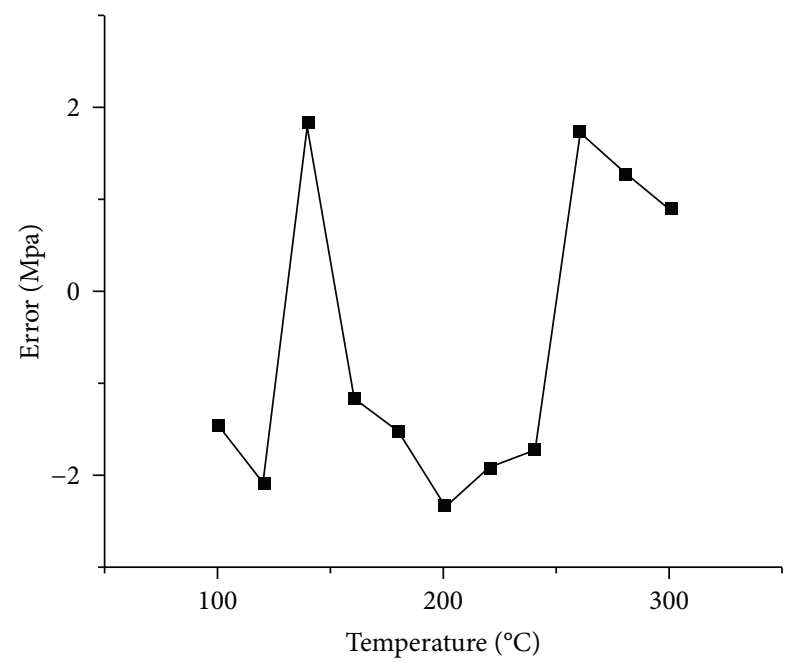

FIgURE 13: Output error curve.

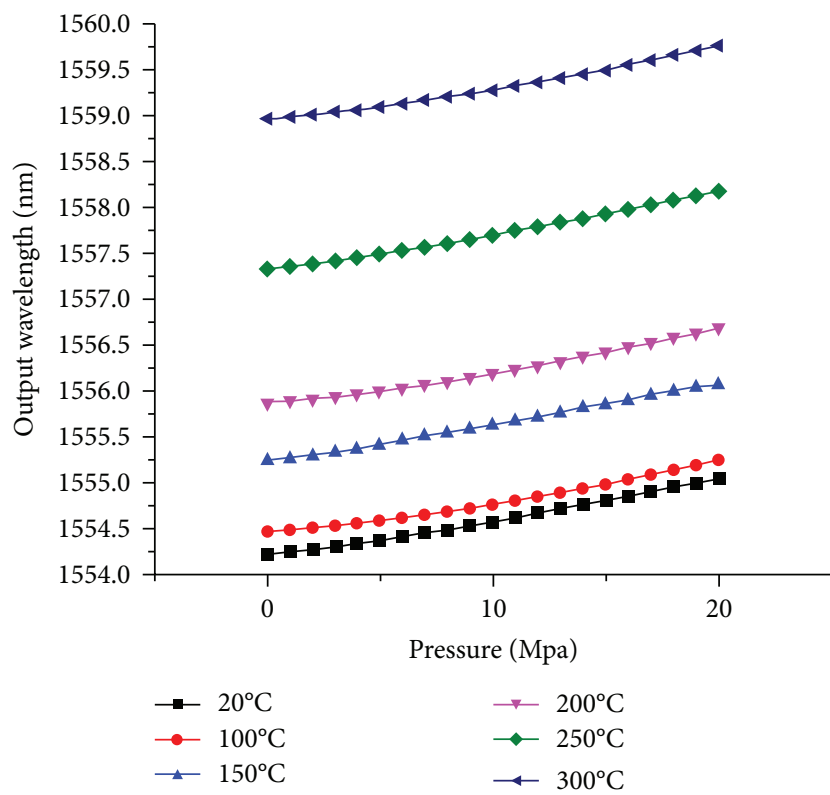

Figure 14: Pressure output curves at different temperatures. forward, and the correctness of the simulation result is verified by the development of the prototype. Using this method, in $50 \mathrm{MPa}$ pressure range and the environment of $300^{\circ} \mathrm{C}$, the relative maximum error is only $4.6 \%$ F.S., and that can greatly improve the accuracy of the test data. Therefore, the method is highly worth popularization. It enhances the accuracy of the test data greatly and has high promotion value. The developed sensor can be applied more extensively in such area as various high-temperature and high-pressure measuring occasions of flammable and combustible, electromagnetic interference, and strong radiation-like pressure monitoring of weapon and explosive.

\section{Data Availability}

The data used to support the findings of this study are included within the article.

\section{Conflicts of Interest}

The authors declare that there are no conflicts of interest regarding the publication of this paper.

\section{Acknowledgments}

This work was supported by the Natural Science Foundation of China (no. 11604304), Scientific and Technological Project of Shanxi Province (201603D121006-1), Science and Technology Innovation Project of University in Shanxi Province (no. 201657), Research Funding Project for returned students from Shanxi (2016-084), and Xinzhou Teachers University scientific research fund project (201719). This study was conducted at Science and Technology on Electronic Test \& Measurement Laboratory in North University of China, Key Laboratory Instrumentation Science \& Dynamic Measurement, Ministry of Education in North University of China, and Metrology Academy of Shanxi Province.

\section{Supplementary Materials}

Supplementary material contains a simulation of the pressurization and heating of the sensor's model. $50 \mathrm{MPa}$ _normal temperature is the simulation when the model is pressurized at $50 \mathrm{MPa}$ in room temperature environment. 300t_no load 
is the simulation analysis of the model without pressure applied at $300^{\circ} \mathrm{C}, 300 \mathrm{t}-50 \mathrm{MPa}$ is the simulation analysis of the model applying pressure of $50 \mathrm{MPa}$ at $300^{\circ} \mathrm{C}$. (Supplementary Materials)

\section{References}

[1] A. D. Kersey, M. A. Davis, H. J. Patrick et al., "Fiber grating sensors," Journal of Lightwave Technology, vol. 15, no. 8, pp. 1442-1463, 1997.

[2] P. Wang, K. Xie, R. Chen et al., "Test verification and application of a longitudinal temperature force testing method for long seamless rails using FBG strain sensor," Journal of. Sensors, vol. 2016, pp. 1-11, 2016.

[3] D. J. Hill and G. A. Cranch, "Gain in hydrostatic pressure sensitivity of coated fibre Bragg grating," Electronics Letters, vol. 35, no. 15, pp. 1268-1269, 1999.

[4] A. Sun, "Study of simultaneous measurement of temperature and pressure using double fiber Bragg gratings with polymer package," Optical Engineering, vol. 44, no. 3, article 034402, 2005.

[5] J. Qi, "A comparison study of the sensing characteristics of FBG and TFBG," Sensor Review, vol. 33, no. 1, pp. 68-79, 2013.

[6] A. Stefani, S. Andresen, W. Yuan, N. Herholdt-Rasmussen, and O. Bang, "High sensitivity polymer optical fiber-Bragggrating based accelerometer," IEEE Photonics Technology Letters, vol. 24, no. 9, pp. 763-765, 2012.

[7] M. H. Yau, T. H. T. Chan, D. P. Thambiratnam, and H. Y. Tam, "Static vertical displacement measurement of bridges using fiber Bragg grating (FBG) sensors," Advances in Structural Engineering, vol. 16, no. 1, pp. 165-176, 2016.

[8] Y. Zhan, K. Gu, H. Wu, and J. Luo, "A combined long period fiber grating multi-parameter sensor," Sensor Review, vol. 33, no. 3, pp. 220-227, 2013.

[9] Y. Liu, Z. Guo, Y. Zhang, K. S. Chiang, and X. Dong, "Simultaneous pressure and temperature measurement with polymercoated fibre Bragg grating," Electronics Letters, vol. 36, no. 6, pp. 564-562, 2000.

[10] Y. Xiong, J. He, W. Yang, L. Sheng, W. Gao, and Y. Chen, "Research on FBG pressure sensor of flat diaphragm structure," in Proceedings of 2012 International Conference on Measurement, Information and Control, Harbin, China, May 2012.

[11] Y. Zhang, D. Feng, Z. Liu et al., "High-sensitivity pressure sensor using a shielded polymer-coated fiber Bragg grating," IEEE Photonics Technology Letters, vol. 13, no. 6, pp. 618-619, 2001.

[12] R. Sekar, B. N. Shivananju, K. P. Lakshmi, and S. Asokan, "Dual functional performance of fiber Bragg gratings coated with metals using flash evaporation technique," Optical Fiber Technology, vol. 18, no. 4, pp. 183-185, 2012.

[13] Z. G. Jia, L. Ren, D. S. Li, and H. N. Li, "Cable stretching construction monitoring based on FBG sensor," in Proceedings Volume 7981, Sensors and Smart Structures Technologies for Civil, Mechanical, and Aerospace Systems, San Diego, California, USA, 2011.

[14] S. Li, "Study and application about differential fiber Bragg grating force-testing ring," in 2010 International Conference on Measuring Technology and Mechatronics Automation, pp. 519-522, Changsha City, China, March 2010.

[15] J. Huang, Z. Zhou, X. Wen, and D. Zhang, “A diaphragm-type fiber Bragg grating pressure sensor with temperature compensation," Measurement, vol. 46, no. 3, pp. 1041-1046, 2012.
[16] V. R. Pachava, S. Kamineni, S. S. Madhuvarasu, and K. Putha, "A high sensitive FBG pressure sensor using thin metal diaphragm," Journal of Optics, vol. 43, no. 2, pp. 117-121, 2014.

[17] G. Allwood, G. Wild, A. Lubansky, and S. Hinckley, "A highly sensitive fiber Bragg grating diaphragm pressure transducer," Optical Fiber Technology, vol. 25, pp. 25-32, 2015.

[18] F. Li, Y. du, W. Zhang, and F. Li, "Fiber Bragg grating soilpressure sensor based on dual L-shaped levers," Optical Engineering, vol. 52, no. 1, article 014403, 2013.

[19] H. Y. Guo and Z. B. Wang, "Research on solid pressure sensor for high-pressure measurement based on fiber Bragg grating," Chinese Journal of Analytical Chemistry, vol. 45, no. 7, pp. 980-986, 2017.

[20] J. Jiang, C. R. Li, M. Guo, and Y. T. Luo, "Development of FBG tension sensor applied to ice monitoring of overhead transmission lines," High Voltage Engineering, vol. 36, no. 13, pp. 30283034, 2010.

[21] J. Dai, M. Yang, X. Yu, and H. Lu, "Optical hydrogen sensor based on etched fiber Bragg grating sputtered with $\mathrm{Pd} / \mathrm{Ag}$ composite film," Optical Fiber Technology, vol. 19, no. 1, pp. 26-30, 2013.

[22] M. Wang, D. N. Wang, M. Yang, J. Cheng, and J. Li, "In-line Mach-Zehnder interferometer and FBG with Pd film for simultaneous hydrogen and temperature detection," Sensors and Actuatiors B: Chemical, vol. 202, pp. 893-896, 2014.

[23] Y. Zhao, Y. Liao, and S. Lai, "Simultaneous measurement of down-hole high pressure and temperature with a bulkmodulus and FBG sensor," IEEE Photonics Technology Letters, vol. 14, no. 11, pp. 1584-1586, 2002.

[24] Y. Guo, D. Zhang, Z. Zhou, F. Zhu, and L. Xiong, "Development and commissioning of FBG sensors for impact test of rock fall protective barrier," Sensor Review, vol. 34, no. 4, pp. 343-348, 2014.

[25] Q. P. Liu, X. G. Qiao, J. L. Zhao, Z. N. Jia, H. Gao, and M. Shao, "Novel fiber Bragg grating accelerometer based on diaphragm," IEEE Sensors Journal, vol. 12, no. 10, pp. 30003004, 2012. 


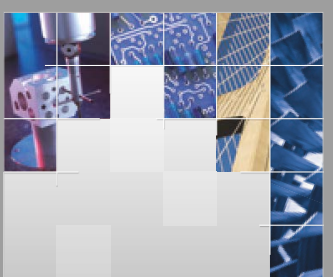

\section{Enfincering}
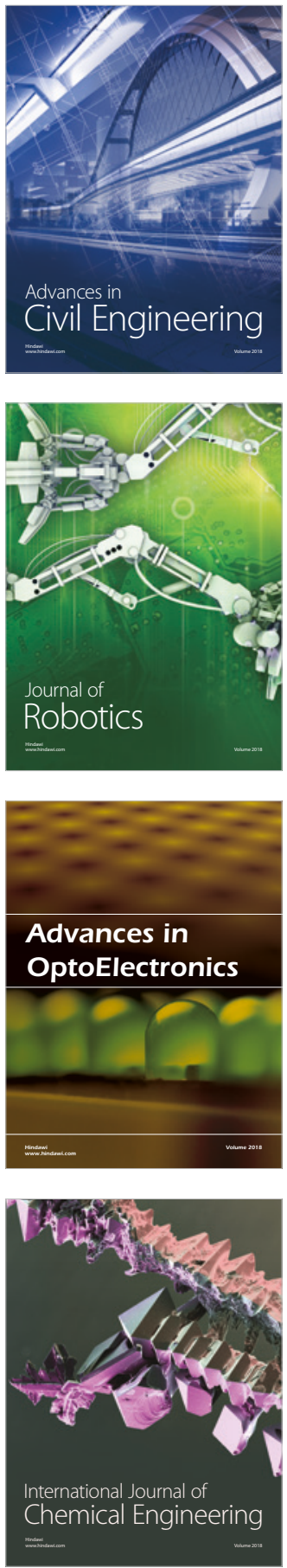

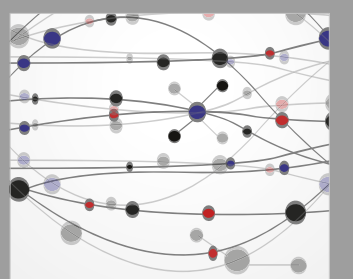

\section{Rotating \\ Machinery}

The Scientific World Journal

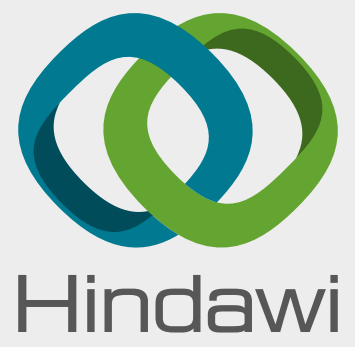

Submit your manuscripts at

www.hindawi.com
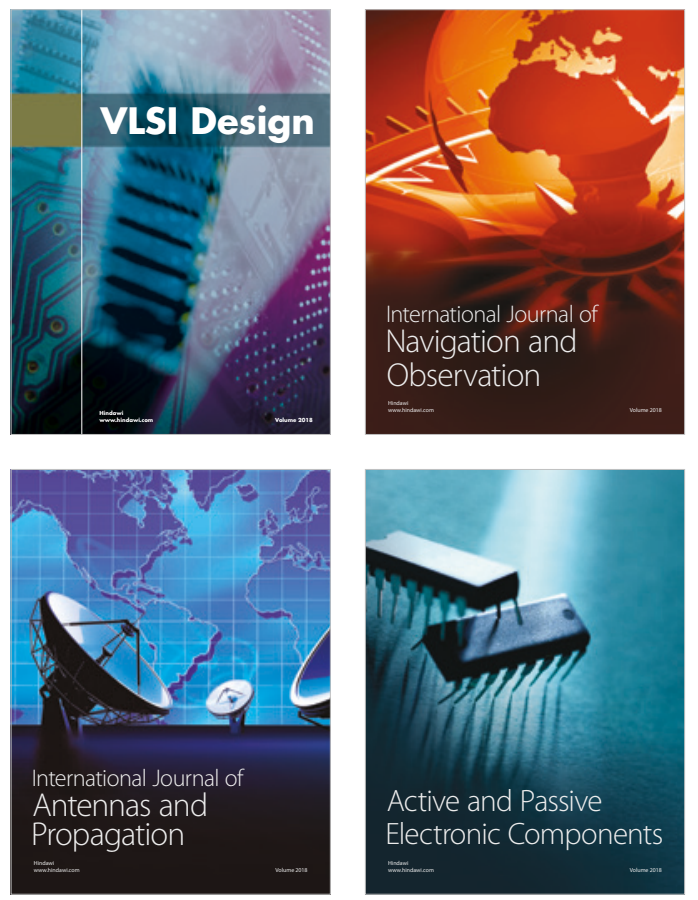
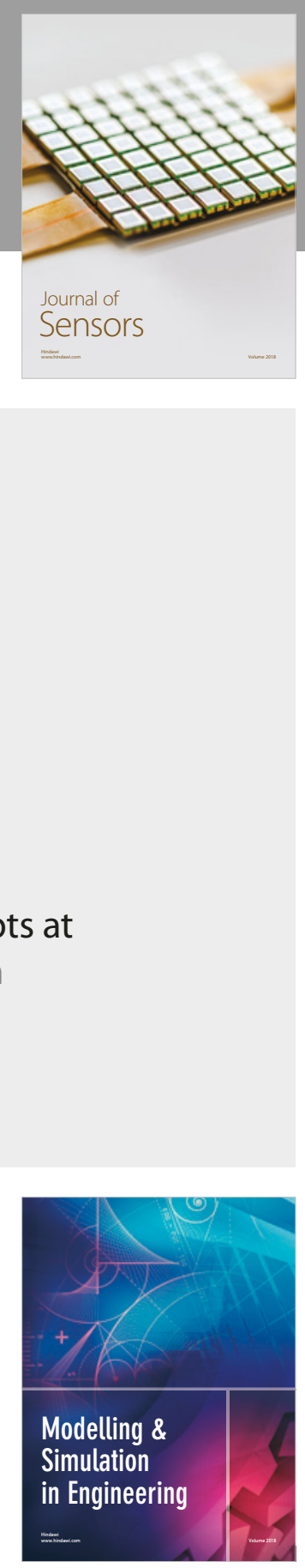

\section{Advances \\ Multimedia}
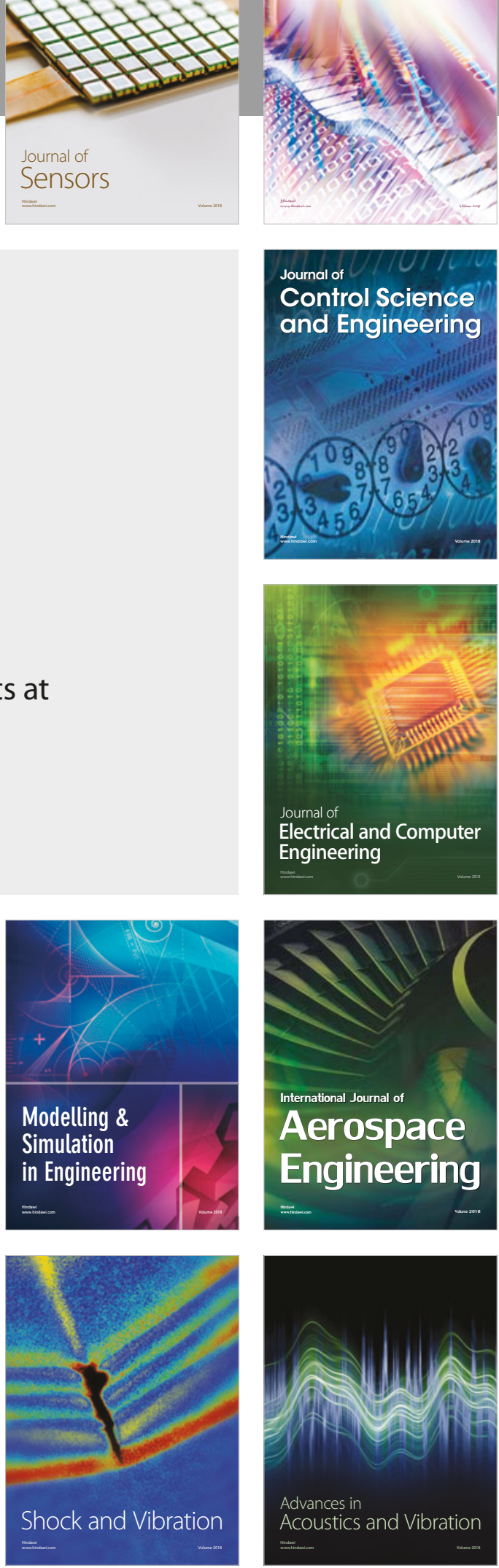